\title{
GERMINAÇÃO E ARMAZENAMENTO DE SEMENTES DE Albizia hasslerii (Chod.) Burkart. ${ }^{1}$
}

\author{
CAMILA KISSMANN², SILVANA DE PAULA QUINTÃO SCALON², \\ ROSILDA MARA MUSSURY3 ANTÔNIO DIAS ROBAINA ${ }^{4}$
}

\begin{abstract}
RESUMO - O objetivo deste trabalho foi de analisar o efeito combinado das temperaturas e dos tratamentos pré-germinativos na germinação das sementes de farinha seca (Albizia hasslerii (Chod.) Burkart.). Foram realizados 2 experimentos. No primeiro as sementes receberam os seguintes tratamentos pré-germinativos: imersão em $\mathrm{H}_{2} \mathrm{SO}_{4}$ PA por 10 minutos, $\mathrm{H}_{2} \mathrm{SO}_{4} 20$ minutos, $\mathrm{GA}_{3} 150$ mg. $\mathrm{L}^{-1}$ por 24 horas, água quente 5 minutos, água natural por 24 horas, e a testemunha, sem tratamento. No segundo experimento, as sementes foram divididas em dois lotes, um lote foi semeado logo após a colheita e o outro foi embalado em papel Kraft e armazenado por 90, 180 e 270 dias em condições de câmara fria e em temperatura ambiente. As sementes receberam os seguintes tratamentos prégerminativos: imersão em $\mathrm{H}_{2} \mathrm{SO}_{4}$ PA por 20 minutos, em água natural por 24 horas, e a testemunha. A incubação ocorreu nas temperaturas de 18,25 e $30^{\circ} \mathrm{C}, 20-30^{\circ} \mathrm{C}$, e em casa de vegetação. Os experimentos foram realizados em DIC, sendo o primeiro em esquema fatorial de 6 x 5 e o segundo em fatorial de 3 x 5 x 4, ambos com 4 repetições de 20 sementes. $\mathrm{O}$ tratamento de imersão em $\mathrm{H}_{2} \mathrm{SO}_{4}$ por 20 minutos apresentou os maiores valores para todas as características avaliadas. As sementes armazenadas por 90 dias em câmara fria apresentaram germinação superior a $50 \%$ sem nenhum tratamento pré-germinativo e em qualquer temperatura de incubação. As plântulas provenientes de sementes armazenadas em câmara fria são mais vigorosas.
\end{abstract}

Termos para indexação: Farinha seca, câmara fria, viabilidade, árvore nativa.

GERMINATION AND STORAGE OF SEEDS OF Albizia hasslerii (Chod.) Burkart.

\begin{abstract}
The objective of this work was to to evaluate the influence of the temperatures and the pre-germinatives treatments in germination of seeds of Albizia hasslerii. Two experiments had been carried out. In the first experiment the seeds had received the following pre-germinative treatments: immersion in $\mathrm{H}_{2} \mathrm{SO}_{4}$ per 10 minutes, $\mathrm{H}_{2} \mathrm{SO}_{4}$ per 20 minutes, $\mathrm{GA}_{3} 150 \mathrm{mg}$. $\mathrm{L}^{-1}$ for 24 hours and the control, without treatment. For the second experiment, the seeds had been divided in two lots, one of them was sown immediately after the harvest and the other was packed in Kraft paper and stored during 90, 180 and 270 days in conditions of cold chamber and ambient temperature. The seeds had received the following pre-germinative treatments: immersion in sulfuric acid for 20 minutes, in natural water for 24 hours, and the witness. The incubation occurred in temperatures of $18^{\circ} \mathrm{C}, 25^{\circ} \mathrm{C}$
\end{abstract}

\footnotetext{
${ }^{1}$ Submetido em 15/05/2008. Aceito para publicação em 24/11/2008.

${ }^{2}$ Bióloga, Mestranda em Produção Vegetal. UFGD - Universidade Federal da Grande Dourados - Faculdade de Ciências Agrárias bibakiss@yahoo. com.br
}

Itahum, Km 12, CEP 79804970, Dourados, MS silvana.scalon@ufgd.edu. br; mara.mussury@ufdf.edu.br

${ }^{4}$ Docente da Universidade Federal da Grande Dourados, Rodovia Dourados Itahum, Km 12, CEP: 79804970, Dourados, MS robaina@ufgd.edu.br 
and $30^{\circ} \mathrm{C}, 20-30^{\circ} \mathrm{C}$ and in greenhouse, without control of temperature. It was evaluated germination percentage, germination speed index, the length of root and aerial part, and dry mass of seedlings. The experiments had been carried out in randomized complete design, being the first one in factorial arrangement of $6 \times 5$ and the second in factorial arrangement of $3 \times 5 \times 4$, both with 4 repetitions of 20 seeds. The sulfuric acid treatment for 20 minutes presented the highest values for all the evaluated characteristics. The seeds stored for 90 days in cold chamber had presented germination superior than $50 \%$ without any pre-germinative treatment and in any temperature of incubation. Seedlings proceeding from seeds stored in cold chamber had been more vigorous.

Index terms: Albizia hasslerii (Chod.) Burkart.), Cold chamber, Viability, native tree.

\section{INTRODUÇ̃̃O}

Atualmente, a busca do conhecimento da biologia de espécies florestais nativas, visando a sua domesticação e o domínio da sua reprodução tem sido cada vez maior. O estudo da germinação de sementes de espécies nativas assume um papel relevante dentro das pesquisas científicas, visto que ocorrem variações significativas intra-específicas na fenologia das espécies em função da época e do local (Rosa, 1998).

A maioria dos projetos que visam à conservação e à exploração de espécies nativas depende da formação de mudas. Tanto a renovação da vegetação, recuperação de áreas degradadas, estabelecimento de bancos de germoplasma, programas de melhoramento e plantio para exploração econômica de frutos, madeiras e produtos medicinais são baseados na coleta de sementes e propagação dessas espécies, sendo fundamentais os conhecimentos sobre a dormência e a germinação das sementes e a propagação vegetativa das espécies nativas (Melo et al., 2000).

O conhecimento das condições ideais para a germinação da semente de uma determinada espécie é de fundamental importância, principalmente, pelas respostas diferenciadas que ela pode apresentar em função de diversos fatores, como viabilidade, dormência, condições de ambiente, envolvendo água, luz, temperatura, oxigênio e ausência de agentes patogênicos, associados ao tipo de substrato para sua germinação (Carvalho e Nakagawa, 2000).

Dentre os fatores do ambiente que afetam o processo germinativo das sementes, a temperatura exerce acentuada influência. As sementes de diferentes espécies apresentem faixas distintas de temperatura para a germinação. Dentro dessas faixas pode ser considerada temperatura ótima aquela na qual a mais alta porcentagem de germinação é obtida dentro do menor espaço de tempo. São consideradas, ainda, as temperaturas mínimas e a máximas, respectivamente como a mais baixa e a mais alta temperatura onde a germinação ocorre (Mayer \& Poljakoff-Mayber, 1989).

Normalmente, as sementes não são utilizadas imediatamente após a coleta. Por isso, devem ser armazenadas para utilização futura no mesmo ano ou até nos anos seguintes, pois as espécies nativas apresentam ciclicidade de produção de sementes, caracterizadas por um ano de alta produção, seguido de um ou dois de baixa produção. Em decorrência disso, existe a necessidade de manter a viabilidade das sementes durante $\mathrm{o}$ armazenamento, minimizando-se a velocidade de deterioração, por meio de tecnologias desenvolvidas e apropriadas a cada espécie. O processo de deterioração é a soma de todas as alterações físicas, fisiológicas, químicas e bioquímicas que ocorrem nas sementes, conduzindo-as à perda total de viabilidade (Fowler, 2000). A rapidez de deterioração das sementes de algumas espécies nativas é muito elevada e o período em que a viabilidade pode ser mantida varia de algumas semanas a poucos meses, de tal maneira que as pesquisas sobre armazenamento de sementes de espécies nativas assumem caráter de extrema importância (Carneiro e Aguiar, 1993).

As condições fundamentais para o armazenamento das sementes são a umidade relativa do ar e a temperatura do ambiente de armazenamento. A magnitude dessas condições pode variar em função das características fisiológicas das sementes, as quais são classificadas em ortodoxas ou recalcitrantes (Vieira et al., 2001). Floriano (2004), em sua revisão, observou que ambiente seco e com baixa temperatura é adequado para o armazenamento de sementes ortodoxas, enquanto que as recalcitrantes devem ser armazenadas em ambiente úmido e com baixa temperatura.

Os ácidos como o ácido sulfúrico, quando em contato 
com os tegumentos duros da semente, podem levar à ruptura da testa, facilitando a embebição e trocas gasosas. A escarificação química, além de desgastar o tegumento espesso, pode também agir removendo a sua impermeabilidade a gases, alterar a sensibilidade à luz e temperatura ou eliminar substâncias inibitórias (Mayer e Poljakoff-Mayber, 1989). As giberelinas possuem efeito estimulatório no processo germinativo quando aplicadas em sementes com dormência e também em não dormentes. As sementes podem necessitar de giberelinas para uma série de eventos: ativação do crescimento vegetativo do embrião, mobilização das reservas do endosperma e no enfraquecimento da camada de endosperma que circunda o embrião, favorecendo assim seu crescimento (Taiz e Zeiger, 1991).

Apesar da eficiência do ácido sulfúrico, sua utilização apresenta uma série de desvantagens, entre as quais o perigo de queimadura ao operador que executa a escarificação, necessidade de um local apropriado para seu descarte, além da dificuldade de empregá-lo em larga escala, devido aos cuidados necessários à sua aplicação e ao custo, quando comparado ao tratamento que utiliza água (Oliveira et al., 2003).

A Albizia hasslerii, Mimosoidea, popularmente conhecida como farinha seca, é uma árvore de 10-20 metros de altura, e que possui propriedade ornamental sendo empregada na arborização de praças públicas e grandes jardins. É uma planta pioneira de rápido crescimento, excelente para reflorestamentos mistos de áreas degradadas. A emergência ocorre entre 10 a 40 dias e, a taxa de germinação geralmente é inferior a 30\% (Lorenzi, 2002).

Como são escassas as informações sobre a germinação de suas sementes, o presente trabalho buscou obter maiores informações sobre o comportamento das sementes de Albizia hasslerii (farinha seca) quanto às diferentes condições de armazenamento e temperaturas de incubação.

\section{MATERIAL E MÉTODOS}

Os experimentos foram realizados no Laboratório de Sementes da Faculdade de Ciências Agrárias da Universidade Federal da Grande Dourados (UFGD). A cidade localizase a $22^{\circ} 13^{\prime} 16^{\prime \prime}$ de latitude Sul e $54^{\circ} 48^{\prime}$ ' "'de longitude Oeste, com altitude de $452 \mathrm{~m}$, estado de Mato Grosso do Sul. O clima é classificado como Cwa e a precipitação média anual é de $1500 \mathrm{~mm}$, com temperatura média anual de $22^{\circ} \mathrm{C}$. As sementes de Albizia hasslerii foram coletadas em área urbana no município de Dourados e o experimento realizado no período de Dezembro de 2005 a Dezembro de 2006. As sementes utilizadas foram obtidas a partir de frutos coletados imediatamente após a maturação fisiológica. Foram retiradas da vagem e homogeneizadas quanto ao tamanho, e foram divididas em dois lotes para a realização de 2 experimentos.

No primeiro experimento as sementes foram lavadas em água corrente e mergulhadas em solução de hipoclorito de sódio a $1 \%$ pelo tempo de 1 minuto para desinfecção fúngica. Logo após, estas sementes receberam os seguintes tratamentos para superação de dormência: imersão em ácido sulfúrico $\left(\mathrm{H}_{2} \mathrm{SO}_{4}\right)$ PA por 10 minutos, imersão em ácido sulfúrico $\left(\mathrm{H}_{2} \mathrm{SO}_{4}\right) \mathrm{PA}$ por 20 minutos, imersão em ácido giberélico $\left(\mathrm{GA}_{3}\right) 150 \mathrm{mg} . \mathrm{L}^{-1}$ por 24 horas, imersão em água quente por 5 minutos, imersão em água natural por 24 horas, e a testemunha, sem tratamento. Em seguida as sementes foram semeadas para germinar em caixas gerbox, sobre duas folhas de papel filtro e acondicionadas em BOD nas temperaturas de $18^{\circ} \mathrm{C}, 25^{\circ} \mathrm{C}, 30^{\circ} \mathrm{C}$ e $20-30^{\circ} \mathrm{C}$ com 4 (quatro) repetições de 20 sementes para cada temperatura e em casa de vegetação $\left(25,1^{\circ} \mathrm{C}\right.$ e $\left.77,3 \% \mathrm{UR}\right)$ com substrato plantimax em bandejas de células. As avaliações feitas neste primeiro experimento representaram o tempo 0 (zero) de armazenamento para a divisão das sementes do segundo experimento em dois sublotes que constituíram dois ambientes de armazenamento, sendo o primeiro ambiente o armazenamento em câmara fria com controle de temperatura e umidade relativa $\left(17^{\circ} \mathrm{C}\right.$ e $69 \%$ UR) e em saco de papel Kraft e, o segundo ambiente as sementes acondicionadas em papel Kraft e foram armazenadas em temperatura ambiente, sem controle de temperatura e umidade relativa (temperatura média do ambiente $=23,6^{\circ} \mathrm{C}$ e $72,7 \% \mathrm{UR}$ ). No segundo experimento, foram avaliados os tratamentos prégerminativos: ácido sulfúrico $\left(\mathrm{H}_{2} \mathrm{SO}_{4}\right) 20$ minutos e imersão em água $24 \mathrm{~h}$ e a testemunha. As sementes foram avaliadas aos, 0, 90, 180 e 270 dias de armazenamento.

Em ambos os experimentos foram avaliados a porcentagem de germinação $(\% \mathrm{G})$, índice de velocidade de germinação (IVG) - conforme metodologia descrita por Maguire (1962) citado por Vieira e Gusmão (2006), comprimento médio de raiz (CMR), comprimento médio de parte aérea (CMPA) e massa seca das plântulas (MS). $\mathrm{O}$ primeiro experimento foi realizado em delineamento inteiramente casualizado em esquema fatorial de 6 (tratamentos pré-germinativos) x 5 (temperaturas de incubação). No segundo experimento, para cada ambiente de armazenamento os experimentos foram conduzidos em delineamento inteiramente casualizado em esquema fatorial de 4 (épocas de semeadura) x 3 (tratamentos pré-germinativos) x 5 (temperaturas de incubação) com 4 repetições de 20 
sementes. Procedeu-se a análise de variância dos resultados e, havendo diferença significativa, as médias de temperaturas e tratamentos foram comparadas pelo teste de Tukey a $5 \%$ de probabilidade e os dados de épocas de avaliação foram submetidos à análise de regressão.

\section{RESULTADO E DISCUSSÃO}

No experimento 1, as sementes de Albizia hasslerii apresentaram grau de umidade de $9 \%$. Com relação à classificação da espécie no armazenamento, informações sobre seu comportamento são escassas. Segundo os resultados obtidos no presente trabalho para Albizia hasslerii a espécie comporta-se como ortodoxa.

$\mathrm{O}$ tratamento de imersão em $\mathrm{H}_{2} \mathrm{SO}_{4}$ por 20 minutos foi o mais eficaz na superação da dormência tegumentar das sementes de farinha-seca, apresentando os maiores valores para todas as características avaliadas, embora não tenha variado significativamente da imersão em $\mathrm{H}_{2} \mathrm{SO}_{4}$ por 10 ' (Figuras 1 e 2 e tabela 1). Apesar dos resultados observados para o tratamento com ácido sulfúrico, a metodologia de superação da dormência de sementes de uma espécie deve ser determinada, levando-se em conta, também, a sua praticidade e o seu custo. Considerando-se os cuidados necessários à aplicação do $\mathrm{H}_{2} \mathrm{SO}_{4}$ e ao custo, foi estudada também a eficácia do tratamento que utiliza apenas imersão em água natural por 24 horas.
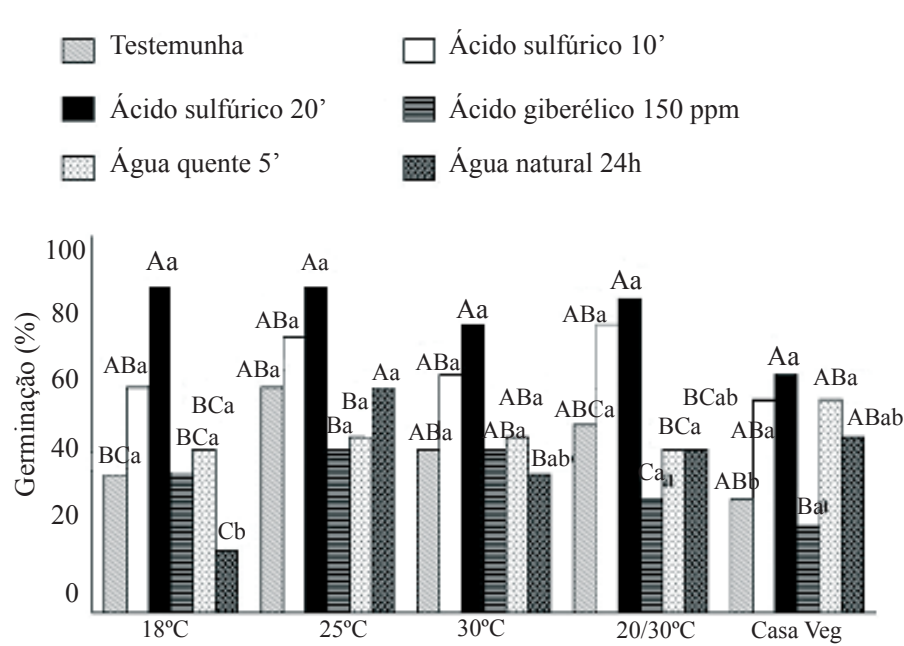

FIGURA 1. Porcentagem de germinação (\%G) de semen-tes de farinha seca (Albizia hasslerii), após a colheita, em função dos tratamentos pré-germinativos e da temperatura de incubação.

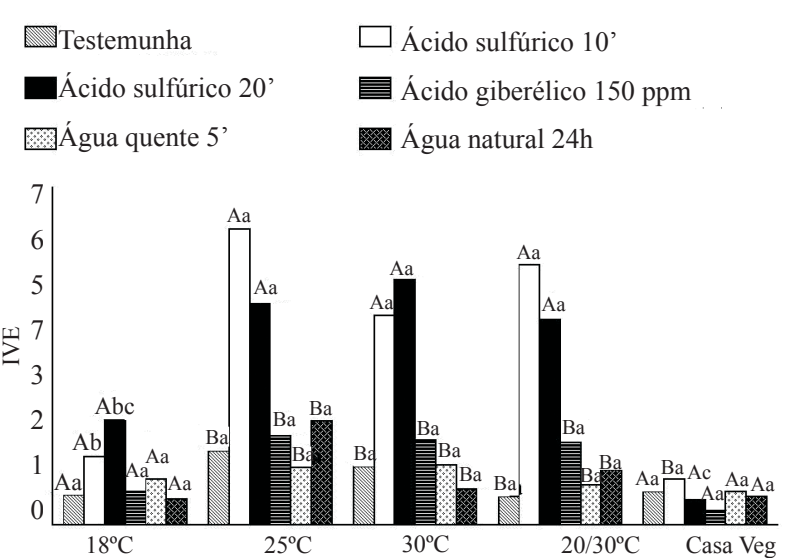

FIGURA 2. Índice de velocidade de germinação (IVG) de sementes de farinha seca (Albizia hasslerii), logo após a colheita, em função dos tratamentos pré-germinativos e da temperatura de incubação.

TABELA 1. Comprimento médio de raiz (CMR), comprimento médio de parte aérea (CMPA), massa fresca (MF) e seca (MS) de plântulas de farinha seca (Albizia hasslerri (Chod. Burkart).

\begin{tabular}{lcccc}
\hline & CMR & CMPA & MF & MS \\
\hline $18^{\circ} \mathrm{C}$ & $0,01 \mathrm{c}$ & $0,01 \mathrm{c}$ & $0,01 \mathrm{c}$ & $0,01 \mathrm{c}$ \\
$25^{\circ} \mathrm{C}$ & $1,49 \mathrm{~b}$ & $3,95 \mathrm{ab}$ & $32,89 \mathrm{bc}$ & $8,23 \mathrm{~b}$ \\
$30^{\circ} \mathrm{C}$ & $0,62 \mathrm{bc}$ & $4,51 \mathrm{ab}$ & $39,44 \mathrm{~b}$ & $11,23 \mathrm{~b}$ \\
$20 / 30^{\circ} \mathrm{C}$ & $1,06 \mathrm{~b}$ & $3,19 \mathrm{~b}$ & $63,05 \mathrm{ab}$ & $13,06 \mathrm{~b}$ \\
Casa veg. & $5,05 \mathrm{a}$ & $5,72 \mathrm{a}$ & $90,83 \mathrm{a}$ & $55,72 \mathrm{a}$ \\
Testemunha & $1,58 \mathrm{a}$ & $3,04 \mathrm{bc}$ & $27,07 \mathrm{~b}$ & $13,81 \mathrm{ab}$ \\
Ácido 10' & $2,09 \mathrm{a}$ & $5,16 \mathrm{ab}$ & $76,80 \mathrm{a}$ & $22,21 \mathrm{ab}$ \\
Ácido 20, & $2,19 \mathrm{a}$ & $5,99 \mathrm{a}$ & $82,60 \mathrm{a}$ & $27,61 \mathrm{a}$ \\
GA15024h & $1,44 \mathrm{a}$ & $2,22 \mathrm{c}$ & $35,41 \mathrm{~b}$ & $20,94 \mathrm{ab}$ \\
Água quente 5, & $1,33 \mathrm{a}$ & $3,02 \mathrm{bc}$ & $28,00 \mathrm{~b}$ & $12,54 \mathrm{ab}$ \\
Água quente 24h & $1,26 \mathrm{a}$ & $1,43 \mathrm{c}$ & $21,61 \mathrm{~b}$ & $8,81 \mathrm{~b}$ \\
\hline
\end{tabular}

Médias seguindas pela mesma letra não diferem entre si pelo teste de Tukey a $5 \%$ de probabilidade

Para as sementes armazenadas à temperatura ambiente não houve interação significativa entre os tempos de armazenamento e as temperaturas de incubação para a porcentagem de germinação, sendo os maiores valores observados para o tempo zero (média de $53,77 \%$ ) e para a temperatura de $25^{\circ} \mathrm{C}$ (média de $31,33 \%$ ). Em condição de 
câmara fria, a porcentagem de germinação foi maior nas temperaturas $18^{\circ} \mathrm{C}(53,7 \%), 25^{\circ} \mathrm{C}(56,6 \%), 30^{\circ} \mathrm{C}$ $(49,7 \%)$ e $20 / 30^{\circ} \mathrm{C}(61,3 \%)$ quando a semeadura ocorreu logo após a colheita e até 180 dias de armazenamento.
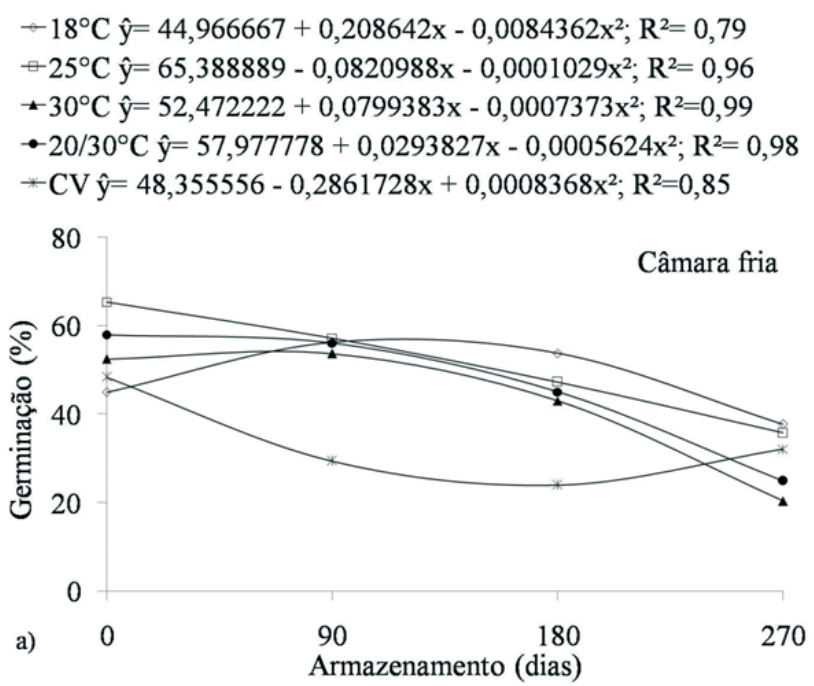

A incubação das sementes em casa de vegetação proporcionou a menor germinação, com redução até os 180 dias, apresentando pequena elevação em seguida (Figura 3).

- Testemunha $\hat{y}=52,500000-0,3129630 x+0,0004321 x^{2} ; R^{2}=0,96$

- $\mathrm{H}_{2} \mathrm{SO}_{4} 20^{\prime} \hat{\mathrm{y}}=70,533333-0,5496296 \mathrm{x}+0,0010699 x^{2} ; \mathrm{R}^{2}=0,99$

^Água $24 h \hat{y}=41,700000-0,2662963 x+0,0004732 x^{2} ; R^{2}=0,97$

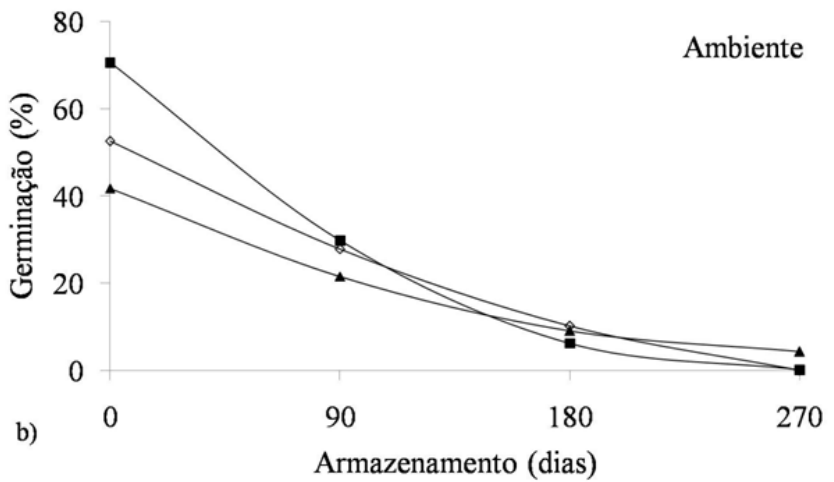

$\rightarrow$ Testemunha $\hat{y}=51,146667-0,0146667 x-0,0000740 x^{2} ; R^{2}=0,91$

- $\mathrm{H}_{2} \mathrm{SO}_{4} 20^{\prime} \hat{\mathrm{y}}=69,083333-0,1712963 \mathrm{x}-0,0000309 \mathrm{x}^{2} ; \mathrm{R}^{2}=0,99$

-Água $24 \mathrm{~h} \hat{y}=41,266667+0,1511111 \mathrm{x}-0,0007408 \mathrm{x}^{2} ; \mathrm{R}^{2}=0,97$

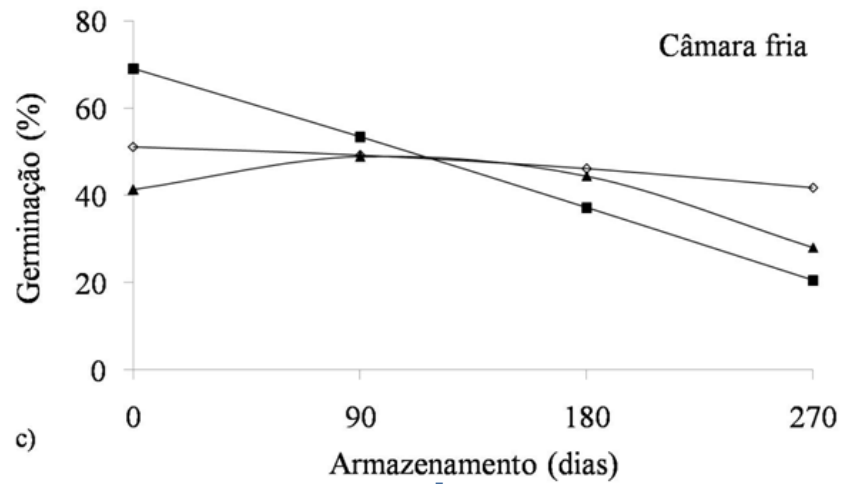

FIGURA 3. Porcentagem de germinação (\%G) de sementes de farinha-seca (Albizia hasslerii (Chod.) Burkart) em função do tempo de armazenamento e da temperatura de incubação (a) ou do tratamento pré-germinativo (b e c).

Para as sementes armazenadas em temperatura ambiente o tratamento comácido sulfúrico por 20 minutos proporcionou maior $\% \mathrm{G}$ e IVG em todas as temperaturas, exceto quando a incubação ocorreu em casa de vegetação (Tabela 2).

Não houve interação significativa entre a temperatura de incubação e os tratamentos pré-germinativos para \%G e IVG para as sementes armazenadas em câmara fria, sendo os maiores valores observados nas temperaturas de $25^{\circ} \mathrm{C}$, $30^{\circ} \mathrm{C}$ e $20 / 30^{\circ} \mathrm{C}$. Os piores valores para ambas variáveis foram observados quando a incubação ocorreu em casa de vegetação. $\mathrm{O}$ tratamento com ácido sulfúrico não diferiu estatisticamente da testemunha nem do tratamento com água para a porcentagem de germinação. Entretanto, este tratamento propiciou maior velocidade de germinação $(1,70)$, diferindo estatisticamente dos demais tratamentos. Almeida et al. (2001), avaliando a germinação de canela-batalha 
(Cryptocaria aschersoniana) observaram maior germinação e índice de velocidade de germinação a $25^{\circ} \mathrm{C}$ e $20-30^{\circ} \mathrm{C}$ e nenhuma germinação a $15^{\circ} \mathrm{C}$, não havendo diferença significativa entre os tratamentos com ácido giberélico $(0$, $150,300$ e $450 \mathrm{ppm})$ e $\mathrm{KNO}_{3}(0 ; 0,25 ; 0,50 \%)$ isolados ou em associação. Sementes de faveiro (Dimorphandra mollis), após 90 e 180 dias de armzenamento, apresentaram maior porcentagem de germinação quando tratadas com $\mathrm{H}_{2} \mathrm{SO}_{4}$ por 10 ou 20 minutos, e acetona por 20 minutos, e incubadas a $25^{\circ} \mathrm{C}$ e $20 / 30^{\circ} \mathrm{C}$, enquanto que o maior IVG foi observado em casa de vegetação no mesmo tratamento (Scalon et al. 2007).

TABELA 2. Porcentagem de germinação (\%G) e índice de velocidade de germinação (IVG) de sementes de farinha seca (Albizia hasslerri (Chod.) Burkart), armazenadas em condições ambiente, em função da temperatura de incubação e do tratamento pré-germinativo.

\begin{tabular}{llllll}
\hline & $18{ }^{\circ} \mathrm{C}$ & $25^{\circ} \mathrm{C}$ & $30{ }^{\circ} \mathrm{C}$ & $20 / 30{ }^{\circ} \mathrm{C}$ & Casa Veg. \\
\hline Testemunha & $19,1667 \mathrm{~B} \mathrm{ab}$ & $30,0000 \mathrm{~A} \mathrm{a}$ & $16,6667 \mathrm{~B} \mathrm{~b}$ & $21,6667 \mathrm{~A} \mathrm{ab}$ & $25,0000 \mathrm{~A} \mathrm{ab}$ \\
$\mathrm{H}_{2} \mathrm{SO}_{4} 20^{\prime}$ & $31,6667 \mathrm{~A} \mathrm{a}$ & $33,3333 \mathrm{~A} \mathrm{a}$ & $27,5000 \mathrm{~A} \mathrm{~b}$ & $28,3333 \mathrm{~A} \mathrm{a}$ & $12,5000 \mathrm{~B} \mathrm{~b}$ \\
Água 24h & $8,3333 \mathrm{C} \mathrm{c}$ & $28,3333 \mathrm{~A} \mathrm{a}$ & $15,8333 \mathrm{~B} \mathrm{bc}$ & $21,6667 \mathrm{~A} \mathrm{ab}$ & $21,6667 \mathrm{ABab}$ \\
\hline \multicolumn{7}{c}{0} & $\mathrm{IVG}$ & & \\
\hline Testemunha & $0,3167 \mathrm{~A} \mathrm{a}$ & $0,6675 \mathrm{~B} \mathrm{a}$ & $0,4629 \mathrm{~B} \mathrm{a}$ & $0,2941 \mathrm{~B} \mathrm{a}$ & $0,2395 \mathrm{~A} \mathrm{a}$ \\
$\mathrm{H}_{2} \mathrm{SO}_{4} 20$ & $0,7658 \mathrm{~A} \mathrm{bc}$ & $1,7400 \mathrm{~A} \mathrm{a}$ & $1,5150 \mathrm{~A} \mathrm{a}$ & $1,2891 \mathrm{~A} \mathrm{ab}$ & $0,1695 \mathrm{~A} \mathrm{c}$ \\
Água 24h & $0,2300 \mathrm{~A} \mathrm{a}$ & $0,7662 \mathrm{~B} \mathrm{a}$ & $0,3237 \mathrm{~B} \mathrm{a}$ & $0,4650 \mathrm{~B} \mathrm{a}$ & $0,2179 \mathrm{~A} \mathrm{a}$ \\
\hline
\end{tabular}

Médias seguidas de mesma letra maiúscula na coluna e minúscula na linha são estatisticamente iguais entre si pelo teste de Turkey a 5\% de significância.

A eficácia do ácido sulfúrico na superação da impermeabilidade do tegumento de sementes foi relatada por diversos autores para várias espécies de leguminosas, em diferentes tempos de embebição, como por exemplo a imersão em ácido sulfúrico por 15 minutos para Peltophorum dubium (Spreng) Taubert. (Oliveira et al., 2003); imersão por 8 a 11 minutos para Bowdichia virgilioides (sucupirapreta) (Sampaio et al., 2001); imersão por 60 minutos para Caesalpinea ferrea var. leiostachia Benth.(pau-ferro) e Cassia grandis L. (cassia grande) e entre 05 e 60 minutos para Samanea saman Merrill (sama) (Lopes et al. 1998).

A maior porcentagem de germinação foi observada nas sementes tratadas com ácido sulfúrico por 20 minutos em semeadura realizada logo após a colheita e após 90 dias de armazenamento tanto em condição ambiente quanto em câmara fria. Entretanto, após esse período de armazenamento, o tratamento com ácido sulfúrico não superou os demais tratamentos, o que não justifica a sua utilização (Figura 4). Observa-se que as sementes armazenadas em ambiente perdem a viabilidade chegando a uma média de $10 \%$ após 180 dias de armazenamento. Sementes de faveiro (Dimorphandra mollis Benth) apresentaram maior germinação quando a semeadura ocorreu logo após a colheita e tratadas com acetona 20 minutos $(53 \%)$ e incubadas a $25^{\circ} \mathrm{C}$ ou em casa de vegetação $(51 \%)$.
Com o armazenamento, as sementes apresentaram redução no potencial germinativo sendo que, após 300 dias, torna-se necessário a utilização de outros tratamentos pre-germinativos sendo o tratamento das sementes com $\mathrm{H}_{2} \mathrm{SO}_{4} / 20$ min $+\mathrm{GA}$ o que proporcionou maior e mais rápida germinação $(41 \%$ e 4,67, respectivamente) (Scalon et al., 2007). Os autores sugerem que o efeito benéfico da aplicação de giberelina após a escarificação, sugere que as sementes, nessa época, se encontravam com baixo nível hormonal associado ao processo de dormência tegumentar. Talvez o mesmo possa ter ocorido com as sementes de Albizia hasslerii, cuja germinação reduziu após 180 dias de armazenamento, porém, a eficácia da giberelina não foi testada no presente estudo. A tolerância ao armazenamento das sementes de diversas espécies nativas é variável. Scalon et al. (2006) recomendam que as sementes de Jacaranda cuspidifolia Mart. (Jacarandá) não sejam semeadas logo depois de extraídas do fruto, considerando-se que a porcentagem de emergência aumentou com o período de armazenamento podendo ser armazenadas por 150 dias sob temperatura ambiente ou refrigeração, sem necessitar de nenhum tratamento para alcançar uma média de 76 e $90 \%$ de emergência, respectivamente, enquanto que em temperatura ambiente, as sementes podem manter a viabilidade por 180 dias, com germinação em torno de $80 \%$. 

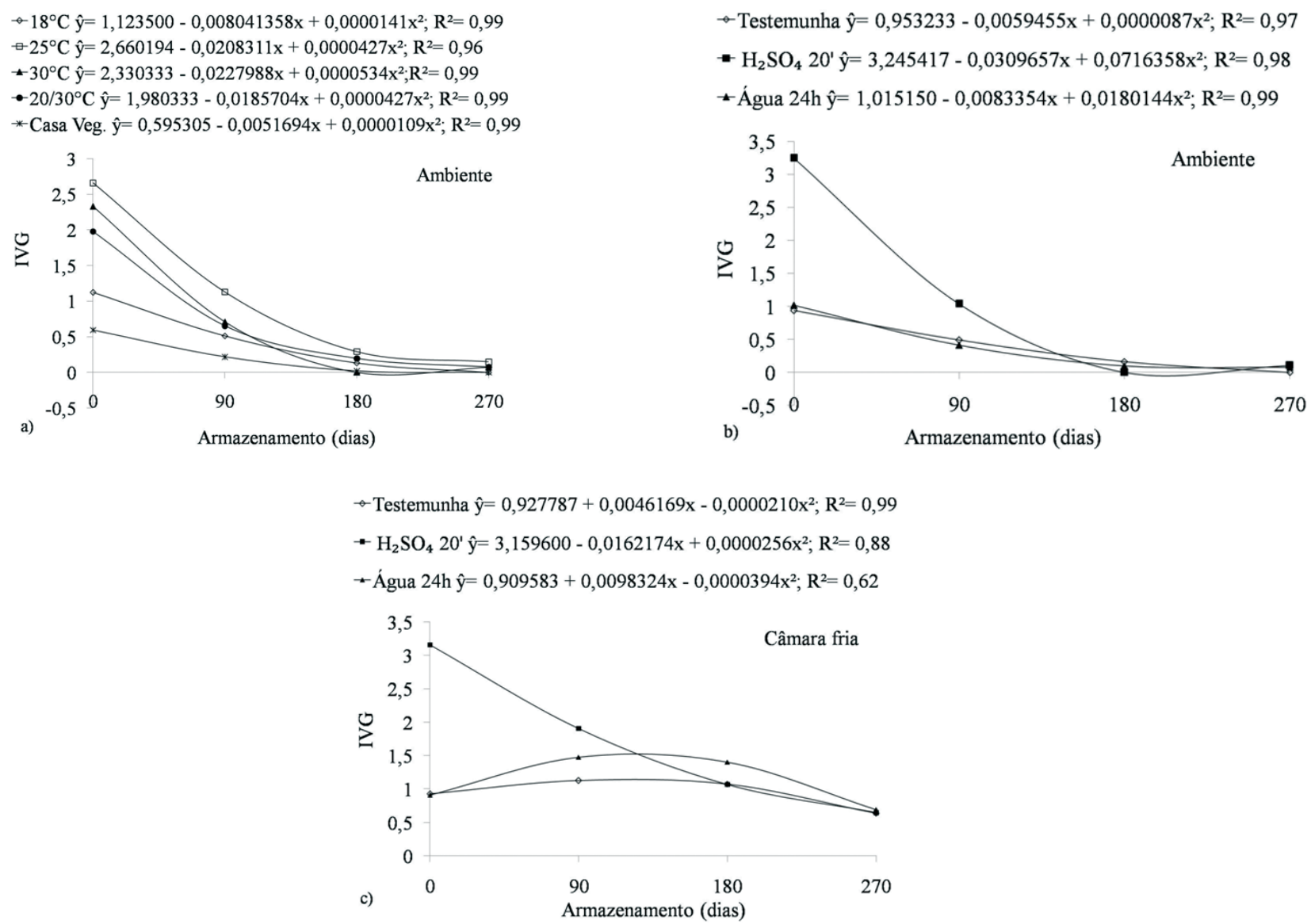

\section{FIGURA 4. Índice de Velocidade de Germinação (IVG) de sementes de farinha-seca (Albizia hasslerii (Chod.) Burkart) em função do tempo de armazenamento e da temperatura de incubação (a) ou do tratamento pré- germinativo (b e c).}

Cabral et al. (2003), trabalhando com armazenamento e germinação de sementes de Tabebuia áurea (manso) Benth. \& Hook. f. ex. S. Moore, observaram que a viabilidade das sementes foi mantida por até 120 dias com altos percentuais de germinação, variando de 88 a 97\%, quando armazenadas em câmara fria. As sementes de Peltophorum dubium (Spreng) Taubert (canafístula) apresentaram redução da porcentagem de germinação após 150 dias de armazenamento em temperatura ambiente, com 45,5\% de germinação, ao passo que aquelas armazenadas à refrigeração $\left(10^{\circ} \mathrm{C}\right)$ mantiveram a mesma porcentagem de germinação do que quando semeadas logo após a colheita, com 63,2\% (Perez et al., 1999). Entretanto, as sementes de Genipa americana L. (jenipapo) possuem um período de viabilidade relativamente curto, com ausência de germinação após 60 dias de armazenamento em temperatura ambiente (Vieira e Gusmão, 2006).
Para as sementes armazenadas à temperatura ambiente, observou-se germinação mais rápida no tempo zero para todas as temperaturas de incubação, seguidas de um decréscimo gradativo ao longo do tempo de armazenamento, sendo maior para a temperatura de $25^{\circ} \mathrm{C}$ (Figura 5). Em condição de câmara fria não houve interação significativa entre tempo de armazenamento e temperatura para o índice de velocidade de germinação, sendo os maiores índices observados no tempo zero e na temperatura de $25^{\circ} \mathrm{C}$, com médias de $1,7 \mathrm{e}$ 1,9 respectivamente.

Os resultados encontrados para IVG, com relação às temperaturas de incubação diferem-se daqueles encontrados por Lopes et al. (2005), que observaram uma maior velocidade de germinação para sementes incubadas em temperatura alternada, enquanto que as temperaturas fixas retardaram a germinação das sementes de Solanum sessiliflorum Dunal 
(cubiu). O tratamento com ácido sulfúrico propiciou maior IVG, em ambas as condições de armazenamento das sementes. Entretanto, observou-se um decréscimo gradativo ao longo do armazenamento, de modo que, após 270 dias de armazenamento não houve diferença entre os tratamentos pré-germinativos (Figura 6). Os resultados observados para o IVG da farinha seca diferem daqueles encontrados por Scalon et al. (2006), trabalhando com sementes de jacarandá, para o qual observaram um maior IVG quando as sementes foram armazenadas sob temperatura ambiente. Entretanto, esses resultados corroboram, em parte, os encontrados por Perez et al., (1999) que observaram para as sementes de Peltophorum dubim (Spreng) Taubert (canafistula) mantidas em temperatura ambiente, diminuição da velocidade de germinação após 90 dias de armazenamento enquanto que, sob refrigeração mantiveram o IVG semelhante ao apresentado antes do armazenamento.
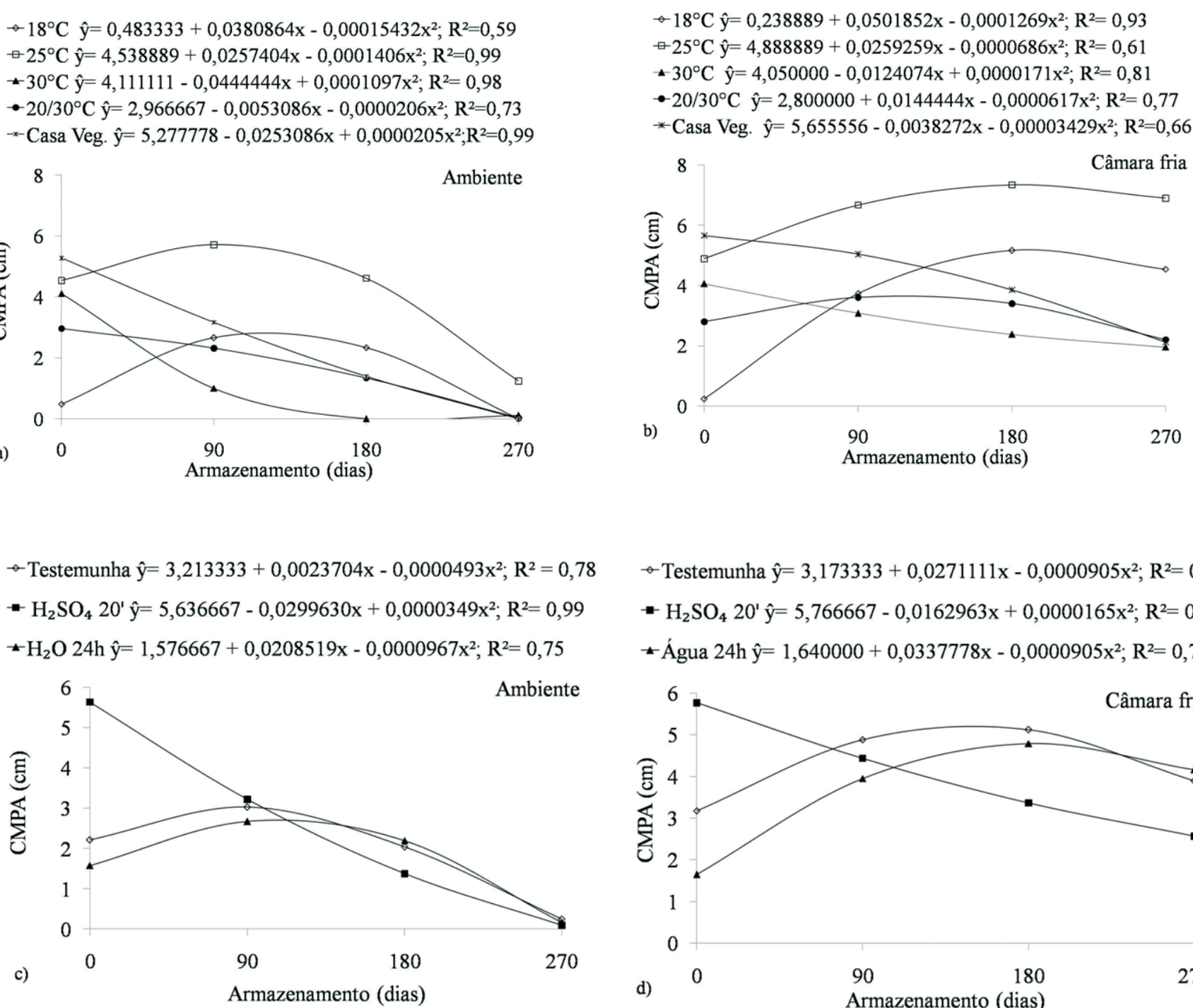

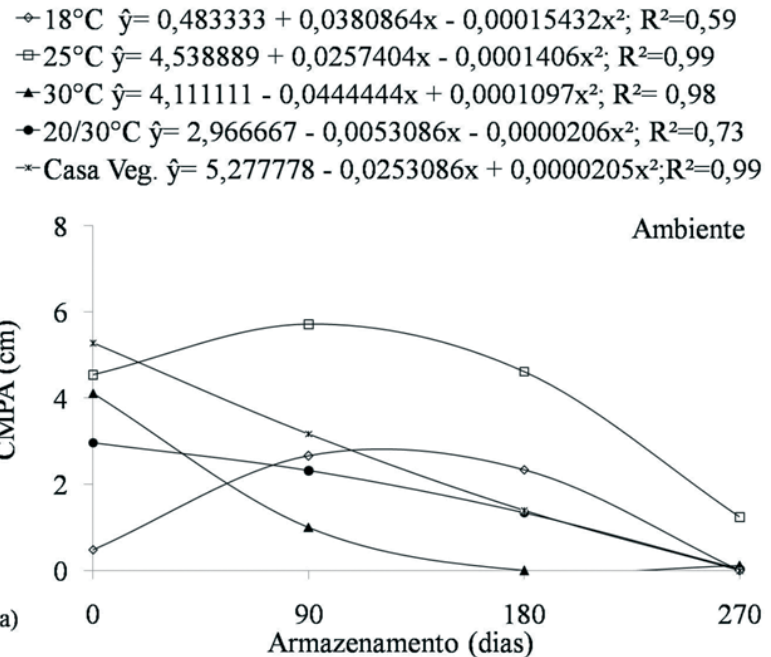

Armazenamento (dias)

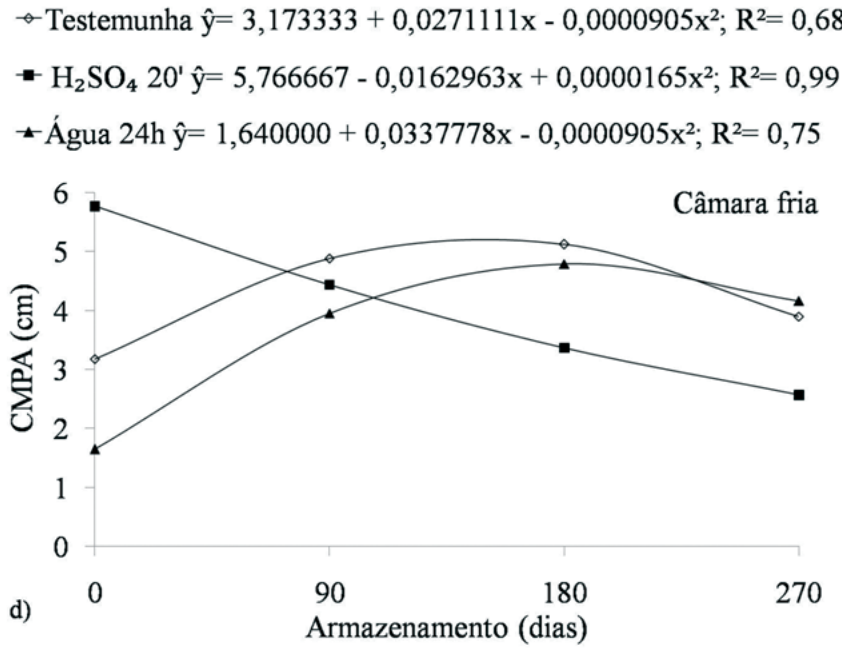

$\rightarrow$ Testemunha $\hat{y}=3,173333+0,0271111 x-0,0000905 x^{2} ; R^{2}=0,68$

$\mathrm{H}_{2} \mathrm{SO}_{4} 20 \hat{\mathrm{y}}=5,766667-0,0162963 \mathrm{x}+0,0000165 \mathrm{x}^{2} ; \mathrm{R}^{2}=0,99$

FIGURA 5. Comprimento Médio de Raiz (CMR) de plântulas de farinha-seca (Albizia hasslerii (Chod.) Burkart) em função do tempo de armazenamento e da temperatura de incubação (a e b) ou do tratamento prégerminativo (c). 
${ }^{-} 18^{\circ} \mathrm{C} \dot{\mathrm{y}}=0,159725$

${ }^{-} 25^{\circ} \mathrm{C} \hat{\mathrm{y}}=1,238889+0,0008025 \mathrm{x}-0,0000171 \mathrm{x}^{2} ; \mathrm{R}^{2}=0,99$

$\star 30^{\circ} \mathrm{C} \hat{y}=0,561111-0,0048765 x+0,0000103 x^{2} ; R^{2}=0,99$

$-20 / 30^{\circ} \mathrm{C} \hat{\mathrm{y}}=0,750000-0,0027778 \mathrm{x}+0,0000035 \mathrm{x}^{2} ; \mathrm{R}^{2}=0,50$

*Casa Veg. $\hat{y}=4,527778-0,0348765 x+0,0000720 x^{2} ; R^{2}=0,81$

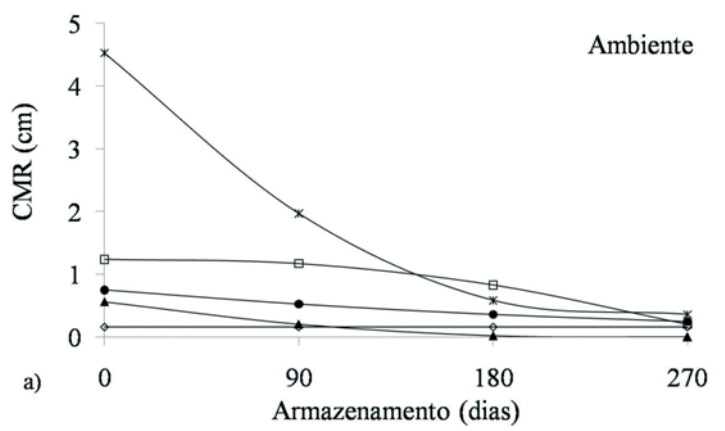

$-18^{\circ} \mathrm{C} \hat{y}=0,000000+0,0148148 x-0,00004115 x^{2} ; R^{2}=0,94$

$\because 25^{\circ} \mathrm{C} \hat{y}=1,216667+0,0091975 x-0,0000309 x^{2} ; R^{2}=0,99$

$+30^{\circ} \mathrm{C} \hat{\mathrm{y}}=0,561111+0,0111728 \mathrm{x}-0,0000446 \mathrm{x}^{2} ; \mathrm{R}^{2}=0,99$

$-20 / 30^{\circ} \mathrm{C} \hat{\mathrm{y}}=0,716667+0,0048765 \mathrm{x}-0,0000240 \mathrm{x}^{2} ; \mathrm{R}^{2}=0,84$

*Casa Veg. $\dot{y}=2,47$

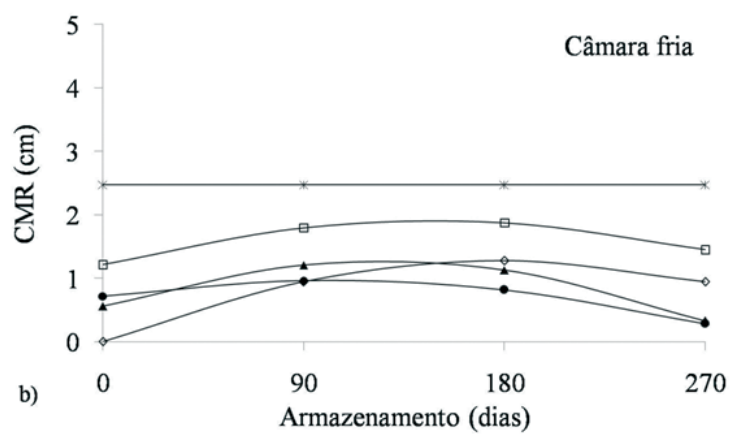

$\rightarrow$ Testemunha $\hat{y}=1,423333+0,0043333 x-0,0000185 x^{2} ; R^{2}=0,74$

- $\mathrm{H}_{2} \mathrm{SO}_{4} 20^{\prime} \hat{\mathrm{y}}=1,666667-0,0074074 \mathrm{x}+0,0000165 \mathrm{x}^{2} ; \mathrm{R}^{2}=0,54$

^Água $24 \mathrm{~h} \hat{\mathrm{y}}=0,883333+0,0135185 \mathrm{x}-0,0000432 \mathrm{x}^{2} ; \mathrm{R}^{2}=0,93$

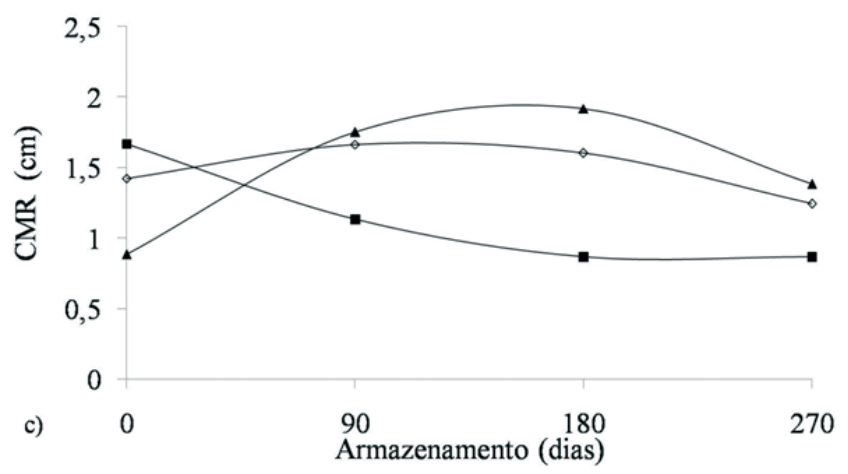

FIGURA 6. Comprimento Médio de Parte Aérea (CMPA) de plântulas de farinha-seca (Albizia hasslerii (Chod.) Burkart) em função do tempo de armazenamento e da temperatura de incubação (a e b) ou do tratamento prégerminativo (c e d).
As plântulas provenientes de sementes incubadas em casa de vegetação apresentaram maior comprimento médio de raiz, entretanto, quando as sementes foram armazenadas em condição ambiente o comprimento reduziu ao longo das avaliações, e não variou quando as sementes foram armazenadas em câmara fria (Figura 7). Quando a incubação ocorreu em BOD o comprimento da raiz foi maior a $25^{\circ} \mathrm{C}$. Observou-se redução nos valores de CMR em plântulas originadas de sementes armazenadas em condição ambiente, com valores tendendo a zero ao final do experimento. A redução nos valores de comprimento de raiz também foi detectada por Souza et al. (2005) para sementes de Tabebuia serratifolia (Vahl.) Nich (ipê-amarelo) armazenadas em ambiente de laboratório.

$\rightarrow 18^{\circ} \mathrm{C} \hat{y}=2,500000+0,1944444 x-0,0007888 x^{2} ; R^{2}=0,5863$

$\because 25^{\circ} \mathrm{C} \dot{\mathrm{y}}=20,472225$

$\star 30^{\circ} \mathrm{C} \hat{\mathrm{y}}=9,488889+0,0295062 \mathrm{x}-0,0002675 \mathrm{x}^{2} ; \mathrm{R}^{2}=0,53$

$-20 / 30^{\circ} \mathrm{C} \dot{\mathbf{y}}=16,288875$

* Casa Veg. $\hat{y}=50,433333+0,1646914 x-0,0013580 x^{2} ; R^{2}=0,86$

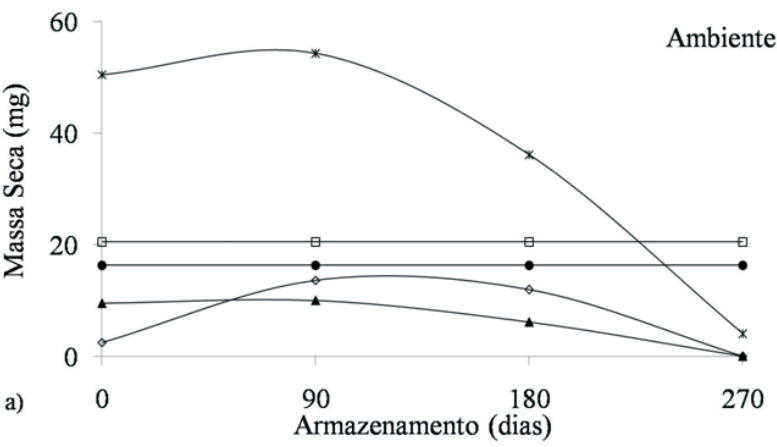

$\rightarrow 18^{\circ} \mathrm{C} \hat{\mathrm{y}}=5,638889+0,1848765 \mathrm{x}-0,0001749 \mathrm{x}^{2} ; \mathrm{R}^{2}=0,55$

$\forall 25^{\circ} \mathrm{C} \dot{\mathbf{y}}=27,06$

$-30^{\circ} \mathrm{C} \hat{\mathrm{y}}=8,511111+0,3550617 \mathrm{x}-0,0014129 \mathrm{x}^{2} ; \mathrm{R}^{2}=0,96$

$-20 / 30^{\circ} \mathrm{C} \dot{\mathrm{y}}=27,94$

*Casa Veg. $\hat{y}=47,361111+0,0910494 x-0,0003944 x^{2} ; R^{2}=0,70$

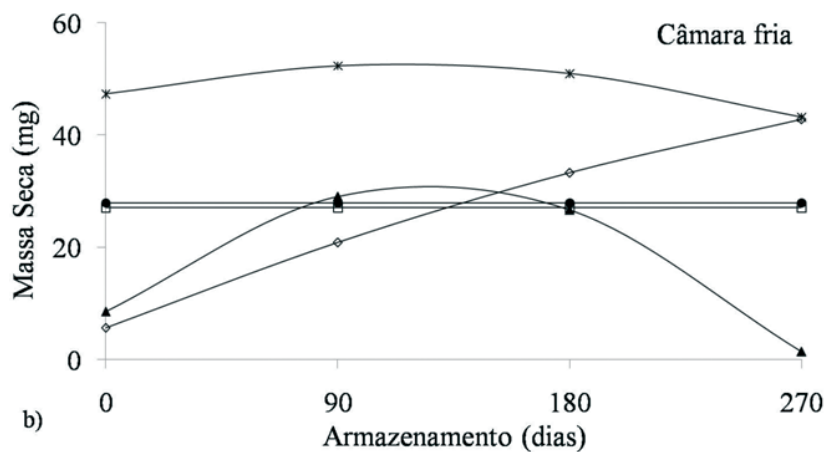

FIGURA 7. Massa Seca (MS) de plântulas de farinhaseca (Albizia hasslerii (Chod.) Burkart) em função do tempo de armazenamento e da temperatura de incubação (a e b). 
Não foi observada interação significativa para tratamentos pré-germinativos e tempo de armazenamento das sementes armazenadas em condição ambiente. Os tratamentos prégerminativos não diferiram entre si, apresentando média de $0,70 \mathrm{~cm}$ de raiz, sendo os maiores valores observados quando a semeadura ocorreu logo após a colheita. Porém, quando provenientes de sementes armazenadas em câmara fria, as plântulas apresentaram maior comprimento de raiz quando as sementes foram imersas apenas em água por 24 h (Figura 8).

Em câmara fria os maiores valores de CMPA foram observados para as plântulas provenientes de sementes incubadas a $25^{\circ} \mathrm{C}$, entretanto, após 90 dias de armazenamento em ambiente e 180 em câmara fria, o comprimento da parte aérea apresentou redução. Em média, o comprimento da parte aérea foi maior nas plântulas provenientes de sementes armazenadas em câmara fria (Figura 9). Com relação aos tratamentos, o CMPA seguiu o mesmo padrão da $\% \mathrm{G}$ e do IVG, apresentando os maiores valores quando as sementes foram tratadas com ácido sulfúrico por 20 minutos e semeadas logo após a colheita, em ambas as condições de armazenamento, porém reduzindo com o armazenamento das sementes. Com 270 dias de armazenamento à temperatura ambiente, as sementes apresentaram os piores resultados, sugerindo perda da viabilidade (Figura 10).

A massa seca foi maior nas sementes incubadas em casa de vegetação e quando em BOD, a massa seca foi maior e não variou durante as avaliações nas temperaturas de $25^{\circ} \mathrm{C}$ e $20-30^{\circ} \mathrm{C}$ (Figura 11). Para as sementes armazenadas em câmara fria, a incubação a $18^{\circ} \mathrm{C}$, embora tenha apresentado o menor valor de massa seca quando a semeadura ocorreu logo após a colheita, mostrou um aumento gradativo ao longo do armazenamento, alcançando, aos 270 dias, valor equivalente ao de quando a incubação ocorreu em casa de vegetação. Para a massa seca das plântulas, não houve interação significativa entre os tempos de armazenamento e os tratamentos pré-germinativos para nenhuma das duas condições de armazenamento das sementes. Os tratamentos pré-germinativos não diferiram estatisticamente entre si em ambas as condições de armazenamento, com médias de 16,54 mg e 29,10 mg para plântulas provenientes de sementes armazenadas em condição ambiente e em câmara fria, respectivamente. Para sementes armazenadas em temperatura ambiente, a massa seca foi maior após 90 dias de armazenamento, enquanto que para sementes armazenadas em câmara fria apresentaram maior MS das plântulas após o armazenamento por 270 dias.

Os valores encontrados para sementes de farinha seca tratadas com ácido sulfúrico não corroboram as observações de Sampaio et al. (2001) onde o tratamento com ácido sulfúrico concentrado supera a dormência tegumentar de sementes de Bowdichia vigilioides H.B.K. (sucupira-preta), porém, resulta em um crescimento anormal das plântulas quando a imersão for acima de 11 minutos comprometendo o crescimento inicial da planta.

De modo geral, tanto as sementes armazenadas em condição de temperatura ambiente como em câmara fria apresentaram um decréscimo gradativo nos valores de \% G, IVG, CMR, CMPA e MS, indicando a perda de viabilidade das sementes ao longo do tempo de armazenamento. A longevidade das sementes está relacionada a muitos fatores, especialmente ao tempo de estocagem, considerando-se que todos os componentes químicos de um ser vivo são instáveis seja em curto ou longo prazo, vindo a se transformar em outros à medida que o tempo passa (envelhecimento), levando as sementes à deterioração gradual e constante em maior ou menor velocidade (Cabral et al., 2003). Souza et al. (2005) também observaram uma redução no vigor de sementes de T. serratifolia armazenadas em condição de câmara fria ao longo do tempo de armazenamento.

Martins et al., (2000) analisando a matéria seca e o comprimento da parte aérea e raiz de plântulas de Euterpe espiritosantensis (palmito-vermelho) após 2 meses de armazenamento, concluíram que o armazenamento por 2 meses em câmaras reguladas nas temperaturas de $10^{\circ} \mathrm{C}$, $15^{\circ} \mathrm{C}$ e $20-30^{\circ} \mathrm{C}$, com e sem a polpa, foi prejudicial ao vigor e ao desenvolvimento destas. $\mathrm{O}$ armazenamento a $5^{\circ} \mathrm{C}$ representou a condição ideal de armazenamento, porém, mesmo nesta temperatura de armazenamento observou-se uma redução nos valores de matéria-seca e comprimento da parte aérea e raiz das plântulas, embora não tenha variado estatisticamente.

Sharma et al. (1999), citado por Sampaio et al. (2001), verificaram que a imersão das sementes de Cleistanthus collinus Benth. em água por 24 horas foi o tratamento mais eficiente, proporcionando maior percentagem de germinação, índice de velocidade de germinação, comprimento de raiz e parte aérea, e peso seco da raiz e parte aérea, seguido da imersão em ácido sulfúrico concentrado por 10 minutos.

As plântulas de farinha seca provenientes de sementes armazenadas em câmara fria apresentaram-se mais vigorosas. Rápida deterioração em ambiente normal de laboratório e eficiente conservação da qualidade fisiológica das sementes quando armazenadas na câmara fria também foram constatadas para sementes de Podocarpus lambertii Klotzch Ex e Ndl. (pinheiro-bravo) e Sebastinania commersoniana 
(Baillon) L. B. Smith \& R.J. Down (branquilho) (Medeiros e Zanon, 1998).

\section{CONCLUSÕES}

- As sementes de Albizzia hasslerri podem ser armazenadas por 90 dias em câmara fria, apresentando germinação superior a $50 \%$ sem nenhum tratamento pré-germinativo e em todas as temperaturas de incubação estudadas.

- As plântulas provenientes de sementes armazenadas em câmara fria são mais vigorosas.

- O tratamento com ácido sulfúrico é benéfico somente quando a semeadura ocorre logo após a colheita.

\section{REFERÊNCIAS}

ALMEIDA, L.P.; ALVARENGA, A.A.; CASTRO, E.M.; LIMA JUNIOR, E.C.; CASTRO, A.H.F. Estudos fisiológicos sobre a germinação de sementes de Cryptocaria aschersoniana Mez. In: CONGRESSO BRASILEIRO DE FISIOLOGIA VEGETAL, 8., Ilhéus. Resumos... 2001. p.40 1 CD-ROOM.

CABRAL, E.L.; BARBOSA, D.C. de A.; SIMABUKURO, E.A. Armazenamento e germinação de sementes de Tabebuia aurea (manso) Benth. \& hook. f. ex. S. Moore. Acta Botânica Brasílica, v.17, n.4, p.609-617, 2003.

CARNEIRO, J.G.A.; AGUIAR, I.B. Armazenamento de sementes. In: AGUIAR I.B. \& FIGLIOLIA, M.B. (Ed). Sementes florestais tropicais. Brasília, DF: ABRATES, p.333-350, 1993.

CARVALHO, N.M.; NAKAGAWA, J. Sementes: ciência, tecnologia e produção. 4.ed. Jaboticabal: FUNEP, 2000. $588 \mathrm{p}$.

FLORIANO, E.P. Germinação e dormência de sementes florestais. Santa Rosa: ANORGS, 2004. 19p.

FOWLER, J.A.P. Superação de dormência e armazenamento de sementes de espécies florestais. In: GALVÃO, A. P. M. Reflorestamento de propriedades rurais para fins produtivos e ambientais. Brasília, DF, Embrapa, 2000. $351 \mathrm{p}$

LOPES, J.C.; CAPUCHO, M.T.; KROHLING, B.; ZANOTTI, P. Germinação de sementes de espécies florestais de Caesalpinea ferrea Mart. ex Tul. var. leiostachya Benth., Cassia grandis L. e Samanea saman Merril, após tratamento para superar a dormência. Revista Brasileira de Sementes, v.20, n.1, p.80-86, 1998.
LOPES, J. C. e PEREIRA, M. D. Germinação de sementes de cubiu em diferentes substratos e temperaturas. Revista Brasileira de Sementes, v.27, n.2, p.146-150, 2005.

LORENZI, H. Árvores brasileiras: manual de identificação e cultivo de plantas arbóreas nativas do Brasil. Nova Odessa: Plantarum, 2002, 148p.

MARTINS, C.C.; BOVI, M.L.A.; NAKAGAWA, J.; GODOY-JÚNIOR, G. Despolpamento e temperatura no armazenamento temporário de sementes de palmito-vermelho (Euterpe espiritosantensis Fernandes). Revista Brasileira de Sementes, v.22, n.1, p.169-176, 2000.

MAYER, A.M.; POLJAKOFF-MAYBER, A. The germination of seeds. 4.ed. Oxford: Pergamom Press, 1989. $270 \mathrm{p}$.

MEDEIROS, A.C.; ZANON, A. Conservação de sementes de branquilho (Sebastiania commersoniana (Baillon) L.B. Smith \& R.J.Down) e de pinheiro-bravo (Podocarpus lambertii Klotzch Ex e Ndl.), armazenadas em diferentes ambientes. Boletim de Pesquisa Florestal, Colombo, n.36, p.29-39, 1998.

MELO, J.T.; SILVA, J.A.; TORRES, R.A.; SILVEIRA, C.E. dos S.;CALDAS, L.S. Coleta, propagação e desenvolvimento inicial de espécies do cerrado. In: SANO, S.M.; ALMEIDA, S.P.(Ed.). Cerrado: ambiente eflora. Planaltina:EMBRAPACPAC, 2000.

OLIVEIRA, L. M. de; DAVIDE, A. C.; CARVALHO, M. L. M. de. Avaliação de métodos para quebra da dormência e para a desinfestação de sementes de canafístula (Peltophorum dubium (Spreng) Taubert. Revista Árvore, v.27, n.5, p.597603, 2003.

PEREZ, S.C.J.G.A.; FANTI, S.C.; CASALI, C.A. Influência do armazenamento, substrato, envelhecimento precoce e profundidade de semeadura na germinação de canafístula (Peltophorum dubim (Spreng) Taubert). Bragantia, v.58, n.1, p.57-68, 1999.

ROSA, S.G.T. Caracterização das sementes de Maytenus ilicifolia Mart. Ex Reiss, espinheira santa e viabilidade de sua propagação sexuada. In: MING, L.C.; SCHEFFER, M.C.; CÔRREA JÚNIOR, C.; BARROS, I.B.I.; MATTOS, J.K.A. Plantas Medicinais aromáticas e condimentos - avanços na pesquisa agronômica, v.2. p.33-51, 1998.

SAMPAIO, L.S. de V.; PEIXOTO, C.P.; PEIXOTO, M.de F. da S.P.; COSTA, J.A.C.; GARRIDO, M. da S.; MENDES, L.N. Ácido sulfúrico na superação de dormência de sementes de sucupira-preta (Bowdichia virgilioides H.B.K. - Fabaceae). Revista Brasileira de Sementes, v.23, n.1, p.184-190, 2001. 
SCALON, S. de P.Q.; MUSSURY, R.M.; FILHO, H.S.; FRANCELINO, C.S.F.; FLORENCIO, D.K.A. Armazenamento e tratamentos pré-germinativos em sementes de Jacarandá (Jacaranda cuspidifolia Mart.). Revista Árvore, v.30, n.2, p.179-185, 2006.

SCALON, S.P.Q.; SCALON FILHO, H.; MUSSURY, R.M.; MACEDO, M.C. de; KISSMANN, C. et al. Potencial germinativo de sementes de Dimorphandra mollis Benth. em função da época de semeadura, tratamentos e temperatura de incubação. Cerne, v. 13, n.3, p.321-328, 2007.

SOUZA, V.C. de; BRUNO, R. de L.A.; ANDRADE, L.A. Vigor de sementes armazenadas de ipê-amarelo Tabebuia serratifolia (Vahl.) Nich. Revista Árvore, v.29, n.6, p.833-
$841,2005$.

TAIZ, L.; ZEIGER, E. Ethylene and abscisic acid. In: Plant physiology: redwood city. Washington: Cummings, 1991.p. 482-487.

VIEIRA, A.H.; MARTINS, E.P.; PEQUENO, P.L.L.; LOCATELLI, M. SOUZA, M.G. de. Técnicas de produção de sementes florestais. Porto Velho: Embrapa, 2001. CT205, p.1-4

VIEIRA, F de A.; GUSMÃO, E. Efeitos de giberelinas, fungicidas e do armazenamento na germinação de sementes de Genipa americana L. (Rubiaceae). Cerne, v.12, n.2, p.136-144, 2006. 